\title{
ANALISIS TINGKAT KECEMASAN DAN AGRESIVITAS ATLET OLAHRAGA BELADIRI PON PAPUA
}

\section{ANALYSIS OF ANXIETY AND AGGRESSION LEVELS OF MARTIAL ARTS ATHLETES PON PAPUA}

\author{
Muhammad Fadli Dongoran*1, Emaluel Lewar², Ibrahim³, Guntur Yuli Satria4 \\ 1,2 Pendidikan Jasmani Kesehatan dan Rekreasi, Universitas Musamus, JL. Kamizun Mopah Lama, \\ Merauke, Papua, 9961, Indonesia \\ 3IImu Keolahragaan/Fakultas Ilmu Keolahragaan, Universitas Cenderawasih Jl. Kamp Wolker, \\ Jayapura, Papua 99224, Indonesia \\ ${ }^{4}$ Pendidikan Jasmani, Universitas Muhammadiyah Kotabumi, Jln. Hasan Kepala Ratu Kotabumi, \\ Lampung Utara, 34517, Indonesia
}

\section{*Corresponding Author: Muhammad Fadli Dongoran, dongoran_pjkr@unmus.ac.id}

Received: 2021-04-21; Revised: 2021-06-14; Accepted: 2021-06-28

\begin{abstract}
Abstrak
Penelitian ini bertujuan untuk mengetahui tingkat psikologis kecemasan dan agresivitas atlet PON Provinsi Papua. Jenis penelitian adalah kuantitatif dengan pendekatan survei untuk mengetahui tingkat psikologis Atlet PON Papua. Populasi penelitian adalah atlet cabang olahraga beladiri Propinsi Papua yang dipersiapkan pada PON ke XX. Teknik pengambilan sampel menggunakan purposive sampling dengan jumlah 93 atlet olahraga beladiri. Instrumen mengadopsi Aggression Questionnaire untuk mengukur tingkat agresivitas, diperoleh 29 item valid mengunakan taraf signifikan 5\%, nilai rtabel $=0.2441$ dan nilai Reabiltas 0.718. Sedangkan The Revised Competitive State Anxiety Inventory-2 dalam mengukur kecemasan, diperoleh 17 item valid dengan nilai rtabel $=0,2039$ dan nilai Reabiltas 0.700. Analisis data menggunakan nilai perbandingan dari tingkatan psikologis dan dimensi yang disesuaikan dengan kriteria yang telah dirumuskan. Hasil penelitian menunjukan tingkat kecemasan pada tingkat sedang jumlah skor rerata 37.73 dengan frekuensi sebanyak 36 atlet dengan dimensi paling tinggi kecemasan kognitif. Begitupun pada tingkat agresivitas pada tingkat sedang dengan jumlah skor rerata 78.7 dengan dimensi paling tinggi agresi verbal.
\end{abstract}

Kata Kunci: Kecemasan, Agresi, Beladiri

\begin{abstract}
This study aims to determine the psychological level of anxiety and Aggression of athletes PON in Papua Province. This type of research is quantitative with a survey approach to determine the psychological level of PON Papua athletes. The population of this research is the martial arts athletes prepared for PON Papua 2021. The sampling technique used purposive sampling with a total of 93 martial arts athletes. The instrument adopted the Aggression Questionnaire to measure the level of aggressiveness obtained 29 valid items with a significant level of 5\%, the value of rtable $=0.2441$ and value a reliability of 0.718 . The Revised Competitive State Anxiety Inventory-2 in measuring anxiety, obtained 17 valid items with value of rtable $=0.2039$ and value a reliability of 0.700. Data analysis uses comparative values of psychological levels and dimensions that are adjusted to the criteria that have been formulated. The results showed that the level of anxiety was at a moderate level with an average score of 37.73 with a frequency of 36 athletes with the highest dimension of cognitive anxiety. Likewise, the level of aggressiveness is at a moderate level with an average score of 78.7 with the highest dimension of verbal aggression
\end{abstract}

Keywords: Anxiety, Aggression, Martial Arts 
How To Cite: Dongoran, M.F.,Lewar E., Ibrahim., Satria, G.Y. (2021). Analisis tingkat kecemasan dan agresivitas atlet olahraga beladiri pon papua. Journal of Sport Education (JOPE), 3 (2), 113-126. doi:http://dx.doi.org/10.31258/jope.3.2.113-126

Journal of Sport Education (JOPE) is an open access article under the CC-BY-SA 4.0

\section{PENDAHULUAN}

Pekan Olahraga Nasional (PON) merupakan pesta olahraga multievent terbesar di Indonesia dan merupakan penyelengaraan pertama di tanah Papua pada tahun 2021. Papua bangkit adalah tagline yang telah digaungkan. Kesempatan langka menjadi tuan rumah untuk pencapaian 5 besar Nasional (Wenda, 2019). Papua ingin sukses penyelengaraan, sukses prestasi, pun sukses ekonomi kerakyatan. Sebanyak 78 medali emas harus menjadi milik kontingen Papua (Ratumakin, 2019). Seperempat target itu untuk olahraga beladiri. Olahraga beladiri menjadi tumpuan Papua untuk memperoleh medali.

Olahraga beladiri adalah olahraga kontak yang ditandai dengan teknik menendang dan meninju (Vertonghen, Theeboom, \& Pieter, 2014). Cabang olahraga beladiri, merupakan jenis olahraga keras yang melibatkan fight full body contact atau pertarungan yang melibatkan seluruh anggota tubuh, dengan teknik dasar tendangan, pukulan, kuncian, dan bantingan yang memiliki resiko cedera yang sangat besar (Amani, 2019).

Kemampuan fisik dan taktik sudah hampir merata pada semua atlet PON. Dalam persaingan yang sangat kompetitif antar atlet beladiri, konsistensi dan mental merupakan aspek penentu kemenangan. Mental toughness harus dianggap penting sebagai bagian dari mempersiapkan atlet untuk jadwal yang menuntut praktek dan kompetisi sebagai latihan fisik (Nurhuda \& Jannah, 2018). Peran mental dalam olahraga prestasi sangat berpengaruh terhadap peningkatan prestasi olahraga (Arifin, 2017). Atlet yang sukses adalah atlet yang memiliki keseimbangan kekuatan fisik, teknik, dan mental. Pada olahraga beladiri aspek mental atau psikologis seperti kecemasan dan agresivitas sangat berpengaruh terhadap penampilan atlet. Prestasi olahraga beladiri pada atlet petarung sangat dipengaruhi oleh tingkat kecemasan dan tingakt agresivitas yang dimiliki oleh seorang atlet (Hasibuan \& Kasih, 2015). Tingkat kedua aspek psikologis itu penting untuk diketahui menjelang PON Papua.

Olahraga beladiri menunjukan intensitas pertandingan yang sangat cepat sehingga kondisi ini yang memaksa atlet lebih mungkin merasakan kecemasan yang tinggi. Atlet yang berpartisipasi dalam olahraga tinju memiliki kecemasan yang lebih tinggi daripada pencak silat (M. Dongoran, Nopiyanto, Saputro, \& Nugroho, 2019). Atlet olahraga beladiri karate mendapat skor yang lebih tinggi secara signifikan dalam kepribadian (Kusuma, Mulyono, \& Wirayudha, 2019). Kecemasan mengacu emosi yang tidak menyenangkan ditandai dengan perasaan yang samar-samar tetapi terus-menerus ketakutan dan kecemasan. Atlet olahraga beladiri harus cerdik menghentikan pikiran yang tidak menyenangkan atau negatif.

Kecemasan akan selalu terjadi pada diri individu apabila sesuatu yang diharapkan mendapat rintangan sehingga kemungkinan tidak tercapainya harapan menghantui pikirannya (Amir, 2012). Jagankan berpikir negatif, kompetitor harus fokus kepada strategi. Sementara itu, gangguan kecemasan yang kompleks dapat membuat keadaan menjadi lebih buruk karena selain fisik yang tidak seimbang, fokus perhatian atlet juga menjadi terpecahpecah. Penelitian (Retnoningsasy \& Jannah, 2020) menunjukan semakin tinggi tingkat mental toughness maka semakin rendah tingkat kecemasan olahraga, yang dapat memberikan respon positif kepada atlet sehingga dapat meredam kecemasan olahraga. Atlet-atlet yang terlibat dalam olahraga individual mengalami cemas lebih tinggi dibandingkan atlet-atlet yang terlibat dalam olahraga kelompok (Athan \& Sampson, 2013). Temuan penelitian lain menunjukan hubungan yang signifikan antara tingkat kecemasan dengan pukulan gate-in pada olahraga woodball (Agustiar \& Sultoni, 2016). Kecemasan merupakan distraktor internal yang berpengaruh terhadap konsentrasi atlet (Jannah, 2017). Berbagai temuan itu menyimpulkan 
bahwa pentingnya seorang atlet memiliki kontrol terhadap kecemasan dalam olahraga beladiri agar atlet mampu menguasai perasaan cemas yang dirasakan yang dapat berpengaruh negatif terhadap performance atlet.

Selain itu karakteristik olahraga beladiri yang keras dan menyerang sering sekali di identifikasikan pada aspek Agresivitas. Didukung dengan temuan yang menunjukan terdapat perbedaan yang signifikan tingkat agresivitas antara remaja yang terlibat dan remaja yang tidak terlibat dalam olahraga beladiri (Usman, 2019). Situasi dan karakteristik pertandingan menuntut olahraga beladiri seperti karateka mengembangkan perilaku agresif (Novian, 2013). Kepribadian individu yang menekuni cabang olahraga beladiri menjadi lebih keras, agresif dan mempunyai keberanian yang tinggi (Hermawati, 2014). Atlet cabang olahraga tinju dan judo lebih agresif dibandingkan dengan atlet cabang olahraga gulat dan kabaddi (Kumar, 2017). Begitupun temuan Radea, (2014) bahwa cabang olahraga pencak silat kategori tanding memiliki tingkat agresivitas yang lebih tinggi dibandingkan dengan cabang olahraga pencak silat kategori seni (tunggal, ganda, regu). Atlet kickboxing menunjukan agresivitas yang lebih tinggi dibanding dengan olahraga renang (Boostani \& Boostani, 2012). Agresivitas pada atlet cabang olahraga beladiri memang manjadi karakteristik yang melekat. Pertandingan olahraga beladiri pada kategori tanding memperlihatkan bahwa atlet dengan agresivitas yang tinggi akan lebih dekat dengan kemenangan.

Namun, pendapat lain di ungkap oleh Karol Gorner, menyatakan pada olahraga kontak agresi bukanlah dasar kompetisi tetapi dapat terjadi selama pertarungan. Ini termasuk olahraga seperti hoki, sepak bola, rugby, di mana saat ini kami melihat semakin banyak cedera, yang disebabkan oleh benturan keras sebagai bagian dari taktik tim. Olahraga beladiri menurunkan tingkat agresi (Gorner, Makarowski, \& Roskova, 2021). Sebuah penelitian yang menarik diterbitkan oleh (Shahar, 2011), yang menemukan pada sampel anak-anak yang kurang mampu secara sosial, yang secara teratur melibatkan anak-anak dalam olahraga mengurangi agresi mereka, meningkatkan pengendalian diri dan disiplin. Vertonghen \& Theeboom (2010) telah melakukan meta-analisis studi seni beladiri dan perilaku agresif, menunjukkan bahwa durasi pelatihan yang lebih lama terkait dengan tingkat agresi yang lebih rendah. Menegaskan tidak terdapat perbedaan yang signifikan antara agresi siswa pada cabang olahraga judo, taekwondo, bola voli, dan sepak bola (Reza, 2012). Perbedaan hasil temuan itu yang berkaitan dengan agresivitas dan kecemasan atlet olahraga beladiri perlu untuk dikaji secara akurat bagaimana kondisi faktual psikologis atlet PON Papua.

Pendekatan ilmiah merupakah langkah strategis dalam mempersiapkan atlet olahraga beladiri untuk mencapai target pada PON Papua 2021. Sumber rujukan jurnal ilmiah menunjukan hanya beberapa peneliti yang memiliki atensi pada atlet PON 2021. Penelitian Putra \& Ita (2019) mengungkapkan temuannya bahwa atlet PON Papua secara umum memiliki kondisi fisik dengan kriteria kurang bahkan pada aspek kecepatan dan V02Max kriteria sangat kurang. Baik atlet laki-laki dan perempuan. Sedangkan pada aspek psikologis secara umum berada dalam kondisi psikologis yang baik (M. F. Dongoran \& Kalalo, 2020). Atensi lain ditunjukan oleh peneliti lain diluar Papua. Motivasi atlet juga dalam kondisi sangat baik dengan sarana yang baik (Nilasari, Syafrial, \& Illahi, 2020). Aspek konsentrasi Atlet Panahan Pelatda Jawa Barat memiliki kriteria yang kurang baik (Hendrayana, 2020). Pentingnya temuan ilmiah atas aspek-aspek diatas merupakan sumbangan yang sangat baik dalam kemajuan ilmu keolahragaan. Meskipun hasil penelitian yang berkaitan dengan upaya mengetahui aspek psikologis atlet sangat minim terutama pembahasan khusus aspek kecemasan dan agresivitas pada olahraga beladiri PON Papua.

Dari literatur di atas memunculkan sebuah pertanyaan bagaimana aspek psikologis kecemasan dan agresivitas atlet olahraga PON Papua? Sehingga penting untuk mengetahui bagaimana intensitas kedua aspek tersebut. Lebih jauh analisis dimensi intesitas dari kedua 
aspek tersebut perlu diketahui. Sehingga akan tampak dimensi seperti apa yang mempengaruhi intensitas para atlet olahraga beladiri PON Provinsi Papua.

\section{METODE}

Penelitian ini menggunakan metode kuantitatif dengan pendekatan survei untuk mengetahui tingkat psikologis Atlet PON Papua (Azwar, 2012). Pengumpulan data dilaksanakan pada bulan Oktober s/d November pada lokasi Pemusatan Latihan masingmasing cabang olahraga Beladiri yang sebagian besar berada di Kota Jayapura.

Populasi dalam penelitian ini adalah atlet Olahraga Beladiri Provinsi Papua yang dipersiapkan mengikuti PON ke-XX. Teknik pengambilan sampel menggunakan purposive sampling dengan syarat atlet Provinsi Papua yang sedang melaksanakan pemusatan latihan. Diperoleh sampel sebayak 93 atlet yang terdiri dari cabang olahraga beladiri berikut; Gulat, Pencak Silat, Taekwondo, Tarung Derajat Tinju, Wushu.

Teknik Pengukuran data menggunakan adaptasi instrumen agresivitas dan kecemasan. Adapun prosedur penelitian dilakukan dengan langkah berikut: Pertama, adaptasi kuesioner dengan melakukan translet ke dalam bahasa Indonesia sesuai dengan sampel yang digunakan. Setelah itu dilakukan expert judgement untuk melihat kesesuaian isi dengan tujuan penelitian hingga dinyatakan layak digunakan dilapangan.

Kedua dilakukan uji validitas dan reabilitasnya sesuai dengan karakteristik sampel. Instrumen mengadopsi Aggression Questionnaire (Buss \& Perry, 1992) untuk mengukur tingkat agresivitas. Skala agresivitas terdiri adri 4 faktor, Physical Aggression (PA), Verbal Aggression (VA), Anger (A) and Hostility (H). Hasil validitas Aggression Questionnaire menggunakan 93 orang sebagai responden, diperoleh 29 item valid. Item tidak valid apabila rhitung < rtabel pada taraf signifikan 5\%, nilai rtabel $=0.2441$. Dengan nilai Reabiltas 0.718. Sedangkan The Revised Competitive State Anxiety Inventory-2 (Cox, Martens, \& Russell, 2003) dalam mengukur kecemasan. Alat ukur ini berisi 17 item pernyataan yang mengukur tiga dimensi dari variabel kecemasan kompetitif. Ketiga dimensi tersebut terdiri dari 5 item gejala kecemasan kognitif, 7 item gejala kecemasan somatik, dan 5 item kepercayaan diri. Hasil validitas The Revised Competitive State Anxiety Inventory-2 menggunakan dengan 93 orang sebagai responden, diperoleh 17 item valid. Item tidak valid apabila rhitung < rtabel pada taraf signifikan 5\%, nilai rtabel $=0,2039$. Dengan nilai Reabiltas 0.700 .

Tahap ketiga persiapan pengambilan data. Pada tahap ini peneliti mengurus izin penelitian dan melakukan pendekatan pada seluruh cabang olahraga beladiri yang menjadi subjek penelitian. Kemudian memaparkan tujuan penelitian kepada pihak-pihak yang berkepentingan sekaligus mengatur jadwal pengambilan data. Selanjutnya tahap pengambilan data. Dsini peneliti memberikan pengarahan pada sampel dalam pengisian kuesioner dan penjelasan umum tujuan penelitian. Pengambilan data dilakukan 30 menit sebelum atlet bertanding uji coba atau sparing dengan lawan. Terakhir peneliti melakukan pengecekan jawaban dan mengumpulkan kembali kuesioner yang telah selesai dijawab oleh responden.

Analisis data menggunakan nilai perbandingan dari tingkatan psikologis dan dimensi yang disesuaikan dengan tujuan penelitian. Sebelum melakukan perbandingan terlebih dahulu menentukan kriteria. Penentuan kreiteria menggunakan rumus dari (Wagiran, 2015) sebagai berikut:

$$
\begin{aligned}
& M i=\frac{(S T+S R)}{2} \\
& S D i=\frac{(S T-S R)}{6}
\end{aligned}
$$

Berikut adalah klasifikasi penentuan kriteria yang dapat dilihat rinciannya pada tabel 1. 
Tabel 1. Rumusan Penentuan Kriteria

\begin{tabular}{ccc}
\hline No & Interval & Kategori \\
\hline 1 & di atas $(\mathrm{Mi}+1,8 \mathrm{SD})$ s.d. $(\mathrm{Mi}+3 \mathrm{SD})$ & Sangat Tinggi \\
2 & di atas $(\mathrm{Mi}+0,6 \mathrm{SD})$ s.d. $(\mathrm{Mi}+1,8 \mathrm{SD})$ & Tinggi \\
3 & di atas $(\mathrm{Mi}-0,6 \mathrm{SD})$ s.d. $(\mathrm{Mi}+0,6 \mathrm{SD})$ & Sedang \\
4 & di atas (Mi - 1,8SD) s.d. (Mi - 0,6SD) & Rendah \\
5 & $(\mathrm{Mi}-3 \mathrm{SD})$ s.d. ( Mi - 1,8SD) & Sangat Rendah \\
\hline
\end{tabular}

\section{Keterangan:}

Mi : Mean ideal

SDi: Standar deviasi ideal

ST : Skor tertinggi

SR : Skor terendah

Berdasarkan rumus penentuan kriteria diatas maka akan diperoleh norma kriteria tingkat Kecemasan dan agresivitas. Norma kriteria yang digunakan dalam penelitian ini menggunakan 5 tingkatan, dari Sangat Tinggi sampai dengan Sangat Rendah. Analisis lebih jauh dengan membandingan skor rerata dimensi dari setiap aspek yag akan dibandingan.

\section{HASIL}

Secara umum tingkat kecemasan atlet beladiri PON Provinsi Papua berada pada tingkat sedang dengan memperoleh skor rerata 38,54. Begitupun pada aspek Agresivitas berada pada tingkat sedang dengan skor rerata 78.20. Kemudian detail masing-masing psikologis atlet dinalisis lebih lanjut. Pada tingkat kecemasan dan agresivitas atlet olahraga Beladiri PON Provinsi Papua dengan jumlah 93 orang akan diperoleh frekuensi dari setiap atlet yang akan ditampilkan pada Tabel 2 dan Tabel 3.

Tabel 2. Frekuensi Tingkat Kecemasan Atlet PON Provinsi Papua

\begin{tabular}{|c|c|c|c|c|}
\hline NO & Interval & Kategori & Frekuensi & Persentase \\
\hline 1 & di atas 57.8 s.d. 68 & Sanggat Tinggi & 0 & $0 \%$ \\
\hline 2 & di atas 49.3 s.d. 57.8 & Tinggi & 7 & $7.5 \%$ \\
\hline 3 & di atas 37.4 s.d. 49.3 & Sedang & 46 & $49.4 \%$ \\
\hline 4 & di atas 27.2 s.d. 37.4 & Rendah & 38 & $40.8 \%$ \\
\hline 5 & 17 s.d. 27.2 & Sangat Rendah & 2 & $2.1 \%$ \\
\hline \multicolumn{3}{|c|}{ Jumlah } & 93 & $100 \%$ \\
\hline
\end{tabular}

Tabel 3. Frekuensi Tingkat Agresivitas Atlet PON Provinsi Papua

\begin{tabular}{ccccc}
\hline NO & Interval & Kategori & Frekuensi & Persentase \\
\hline 1 & di atas 121.4 s.d. 145 & Sanggat Tinggi & 0 & $0 \%$ \\
2 & di atas 98.58 s.d. 121.4 & Tinggi & 7 & $7.5 \%$ \\
3 & di atas 75.42 s.d. 98.58 & Sedang & 49 & $52.7 \%$ \\
4 & di atas 52.26 s.d. 75.42 & Rendah & 36 & $38.7 \%$ \\
5 & 29 s.d. 52.6 & Sangat Rendah & 1 & $1 \%$ \\
\hline Jumlah & & 93 & $100 \%$ \\
\hline
\end{tabular}

Berdasarkan tabel diatas menunjukan tingkat kecemasan atlet PON Papua secara umum berada pada tingkat sedang dengan frekuensi 46 atlet. Tingkat kecemasan tinggi dengan frekuensi 7 atlet. Tingkat kecemasan rendah dengan frekuensi 38 atlet dan sangat rendah 2 atlet. Sedangkan pada tingkat agresivitas atlet PON Papua secara umum berada pada tingkat 
sedang dengan frekuensi 49 atlet. Tingkat kecemasan tinggi dengan frekuensi 7 atlet. Tingkat kecemasan rendah dengan frekuensi 36 atlet dan sangat rendah 1 atlet.

Berdasarkan tingkat psikologis kecemasan dan agresivitas di atas maka dilakukan analisis lebih jauh. Analisis dilakukan untuk melihat kontribusi dari setiap dimensi masingmasing komponen psikologis. Sejauh mana tingkat dimensi itu pada setiap atlet. Analisis dilakukan dengan membandingkan hasil rerata setiap dimensi psikologis yang dapat dilihat pada Gambar 1 dan Gambar 2.

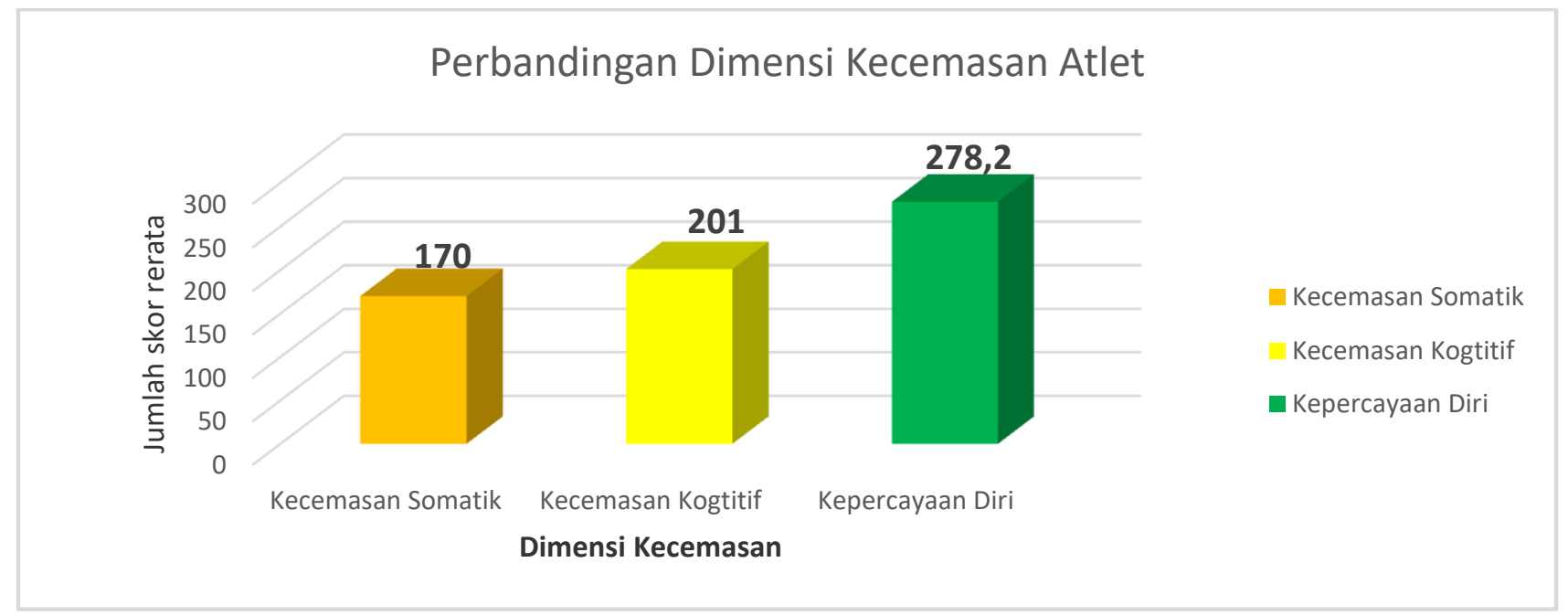

Gambar 1. Perbandingan Dimensi Tingkat Kecemasan Atlet

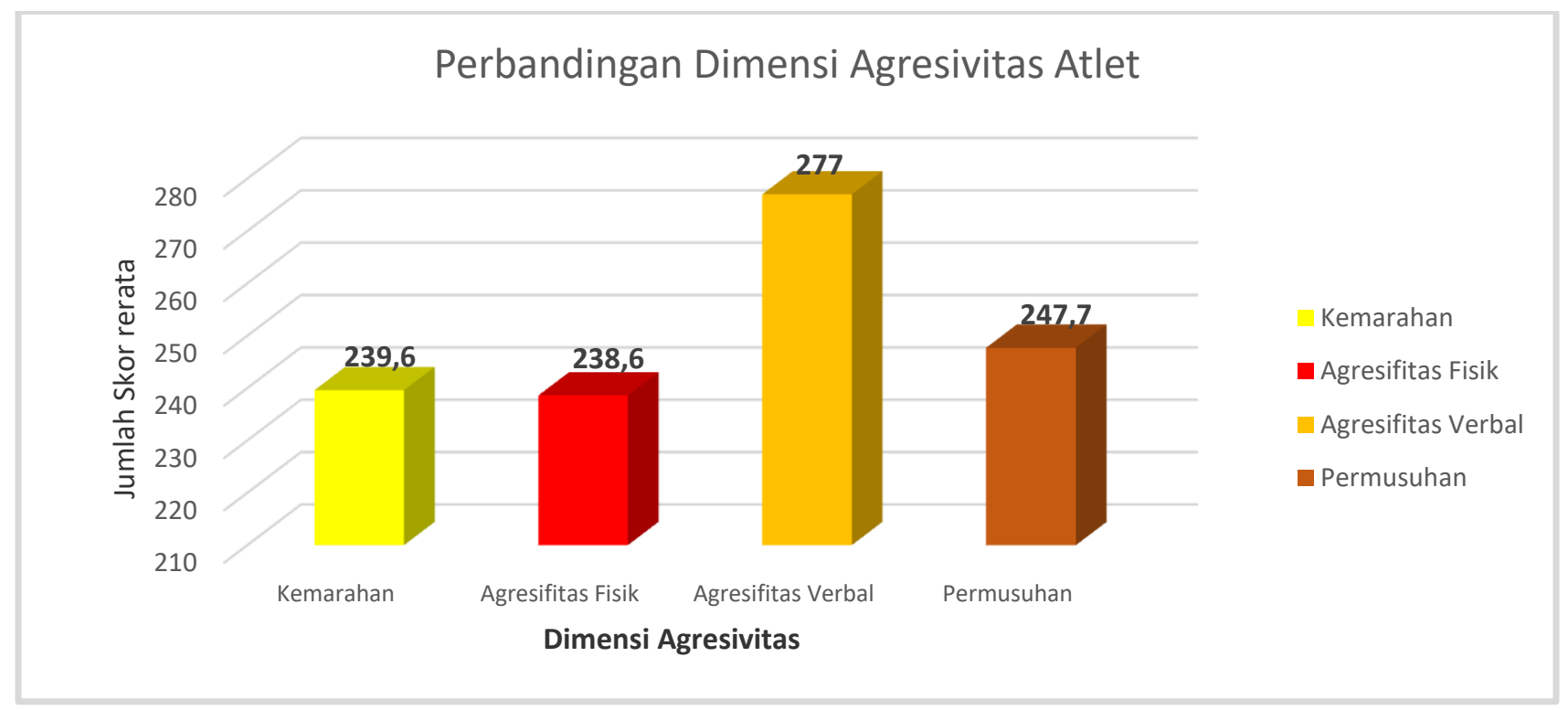

Gambar 2. Perbandingan Dimensi Tingkat Agresivitas Atlet

Berdasarkan Gambar 1 dapat terlihat dimensi kepercayaan diri memiliki skor tertinggi dengan skor 278.2. Sedangkan pada kecemasan menunjukan kecemasan kognitif jauh lebih tinggi dengan skor 201 dibandingka dengan dimensi somatik 178. Pada Gambar 2 terlihat dimensi agresivitas verbal memiliki nilai tertinggi 277. Permusuhan lebih tinggi dengan 247.7 dibandingkan dengan kemarahan skor 239.6 dan agresivitas fisik 238.6.

\section{PEMBAHASAN}

Hasil penelitian menunjukan bahwa tingkat kecemasan atlet beladiri PON Provinsi Papua pada kategori medium atau sedang. Ditemukan sebanyak 46 atlet dengan presentasi 
49.4\% pada tingkat kecemasan medium. Membuktikan bahwa kualitas mental Atlet Papua sangat baik dengan sebagian besar atlet berada pada kriteria kecemasan sedang. Atlet olahraga beladiri yang sukses harus merasa dalam keadaan kecemasan mudah dikelola yang cukup untuk tetap terangsang, tertantang, dan waspada saat memantau dan bereaksi terhadap rangsangan eksternal (Dosil, 2006). Kecemasan sedang yang mudah dikelola adalah seperangkat keterampilan atlet untuk mengendalikan perasaan cemas baik dari dalam diri atlet maupun dari lingkungan yang dihadapinya untuk tidak terlalu merasakan cemas yang berlebih atau sangat tinggi sehingga dapat dikelola dan dimanfaatkan sebagai alarm kewaspadaan pada atlet dan meningkatkan penampilan atlet.

Karakteristik psikologis yang akan mempengaruhi keberhasilan atlet dalam olahraga terdiri dari motivasi, kepercayaan diri, kontrol kecemasan, pentingnya tim, persiapan mental, dan konsentrasi (Nopiyanto \& Dimyati, 2018). Sedangkan, pada olahraga beladiri karate kumite dibutuhkan self regulation, mengontrol situasi selama bertanding, kontrol perhatian, optimalisasi stress, kontrol kecemasan, kepercayaan diri (Kurtovic \& Savova, 2016). Kecemasan olahraga ditemukan menjadi salah satu faktor penting dalam diri atlet (Kalinin, Balazsi, Pentek, Duica, \& Hantiu, 2019). Banyak atlet yang gagal mewujudkan kemampuan optimalnya karena rasa cemas dan takut gagal yang berlebihan (Ardianto, 2013). Kecemasan dapat berkaitan dengan performa yang optimal jika pemain tersebut mengartikan perasaan cemas mereka sebagai fasilitatif yang tidak melemahkan, kecemasan diperlukan untuk menjaga kewaspadaan dan fokus perhatian.

Ditemukan hanya 7.5\% atlet dengan Frekuensi 7 atlet dengan tingkatan kecemasan tinggi. Secara umum diterima bahwa peningkatan kecemasan adalah penyebab kinerja yang buruk pada banyak atlet (Zadkhosh, Zandi, \& Hemayattalab, 2018). Ketika seorang atlet mengalami kecemasan olahraga yang tinggi maka hal itu akan berdampak pada kondisi fisik atau fisiologisnya, seperti ketegangan otot yang kemudian berpengaruh pada kemampuan teknis (Maulana \& Khairani, 2017). Penelitian telah dilakukan untuk membandingkan hubungan antara tingkat kecemasan olahraga dengan jenis cabang olahraga, yang sebagian besar menyatakan bahwa atlet yang tergabung dalam olahraga individual menunjukan tingkat kecemasan yang lebih tinggi daripada atlet dari olahraga tim (Jannah, 2016). Studi pada olahraga beladiri menunjukan dominasi pemicu kecemasan atlet yaitu pikiran ingin segera bertanding dan memikirkan strategi untuk mengalahkan lawan. Selain itu, ketakutan akan salah teknik, takut akan catatan lawan yang lebih baik, merasa kurang latihan sering sekali menghantui atlet olahraga beladiri (Purnamasari, Febriani, \& Kusnandar, 2020). Kurangnya pengalaman atlet dalam berkompetisi dan mengelola emosi lebih mudah mengalami kecemasan (Kar, 2013).

Faktor pertimbangan yang harus diperhatikan atas hasil penelitian ini adalah waktu pengambilan data. Meskipun hasil menunjukan kecemasan atlet tidak pada tingkatan yang tinggi namun kondisi atlet dan waktu pertandingan harus juga menjadi perhatian. Competitive state anxiety yang dirasakan oleh atlet semangkin meningkat dari satu minggu sampai satu jam sebelum pertandingan dimulai (Mabweazara, Andrews, \& Leach, 2014). Artinya kondisi pertandingan pengambilan data saat uji coba atau sparing tentu berbeda dalam pertandingan sesungguhnya yang berpengaruh pada tingkat kecemasan atlet. Hasil penelitian (Ilsya, 2016) menyimpulkan bahwa hasil tingkat kecemasan bagi tim putra yang semakin mendekati waktu pertandingan maka tingkat kecemasannya semakin meningkat.

Penemuan penelitian ini menunjukan dimensi kemasan yang paling tinggi pada atlet olahraga beladiri PON Papua adalah kecemasan kognitif. Meskipun laporan lain menunjukan Atlet individu melaporkan skor kecemasan kognitif yang lebih rendah daripada atlet olahraga tim (Muhammad, Khan, \& Khan, 2020; Radochonski, Cynarski, Perenc, \& Siorek-Maślanka, 2011). Kecemasan somatik mengacu pada manifestasi fisik kecemasan yang terkait dengan gejala tubuh seperti: ketegangan otot, sesak napas dan detak jantung yang cepat sedangkan, 
kecemasan kognitif mengacu pada perasaan kekhawatiran dan tekanan emosional yang dirasakan seorang atlet untuk pertandingan yang akan datang (Ree, French, MacLeod, \& Locke, 2008). Menguatkan pernyataan itu hasil penelitian Ilsya, (2016) menemukan dalam kasus kecemasan kognitif, tidak terdapat beban di semua waktu pada laki-laki, tetapi pada perempuan menunjukan peningkatan yang progresif ketika kompetisi semakin dekat. Kecemasan kognitif dapat mengganggu konsentrasi dan fokus atlet (Nikseresht, Yabande, Rahmanian, \& Jahromi, 2017). Timbulnya kecemasan kognitif meliputi ketidakpastian dan kekhawatiran pikiran-pikiran negatif tentang situasi yang dihadirkan, dan potensi bahaya yang mungkin terjadi biasanya dalam waktu dekat. Sementara beberapa tingkat kecemasan seringkali menguntungkan atlet karena meningkatkan tingkat kewaspadaan dan fokus perhatian, fokus perhatian internal, namun ketegangan otot menyertai jika tingkat kecemasan terlalu tinggi biasanya menghasilkan penampilan yang buruk. Perhatian utama di sini adalah sumber pemikiran ini dalam menilai situasi sebagai ancaman.

Pada aspek agresivitas menunjukan juga atlet beladiri PON Provinsi Papua dikategori medium atau sedang. Ditemukan sebanyak 49 atlet dengan presentasi $52.7 \%$ pada tingkat agresivitas medium. Hanya 7.5\% atlet dengan kriteria agresivitas tinggi. Sejalan dengan temuan bahwa semakin tinggi partisipasi dalam olahraga beladiri karate, maka semakin rendah agresivitas (Ahmad \& Diana, 2015). Agresi sering didefinisikan sebagai perilaku sosial terbuka yang melibatkan setidaknya dua orang, dimana tindakan fisik dan/atau verbal permusuhan disampaikan kepada orang lain dengan niat langsung untuk menyebabkan kerusakan (Bushman \& Huesmann, dalam Shachar, Ronen-Rosenbaum, Rosenbaum, Orkibi, \& Hamama, 2016). Agresivitas diperlukan dalam olahraga sepanjang masih dalam batas-batas tidak merugikan diri sendiri dan lawan serta tidak melanggar peraturan permainan (Verawati \& Sari, 2018). Atlet untuk bermain agresif itu harus terarah, disiplin, tanggung jawab, sportif, dan meningkatkan penguasaan diri agar dapat mengontrol diri sendiri (Syahlan, 2016). Agresivitas disini tentunya tidak diartikan sebagai bentuk serangan yang kejam atau destruktif, tetapi dikaitkan erat dengan ciri khas olahraga itu sendiri yaitu olahraga beladiri yang memang membutuhkan sikap agresif.

Hasil diatas membuktikan atlet PON Papua dapat dikatakan sebagai atlet elit dengan sikap yang profesional cenderung mampu untuk mengontrol emosi dalam situasi pertandingan. Sikap agresivitas pada atlet dapat diatasi jika seorang atlet memiliki kemampuan regulasi emosi yang baik (Carysa, 2019). Dikuatkan dengan penemuan terdapat hubungan antara regulasi emosi dan agresivitas pada atlet tinju Batalyon Artileri Peratahanan Udara Sedang (Kadek Sri Harta Dvikaryani, Ni Jannah, 2020). Selain itu kondisi, waktu, dan lawan bertanding juga harus menjadi perhatian dalam pengambilan kesimpulan.

Agresi dan kekerasan telah menjadi hal biasa di zaman modern ini kompetisi olahraga, terutama yang memiliki emosi tingkat tinggi seperti olahraga beladiri (Krishnaveni \& Shahin, 2014). Aktivitas olahraga rentan terhadap munculnya tindakan agresif, terutama untuk jenis olahraga yang memperbolehkan kontak tubuh secara langsung dengan lawan serta olahraga yang bersifat beregu (Kardiyanto, 2014). Apapun tingkat agresinya, itu bisa diminimalkan dengan mengadopsi pendekatan sistematis ditingkat psikologis dan sosiologis dengan pelatihan yang tepat. Stereotip sosial yang sangat kuat yang mempersepsikan olahraga beladiri sebagai cara mengembangkan agresi (Kusnierz \& Bartik, 2014).

Selain itu, temuan yang cukup menarik adalah tingkat dimensi agresivitas verbal memiliki nilai tertinggi. Permusuhan lebih tinggi dibandingkan dengan kemarahan dan agresivitas fisik. Sedangkan kemarahan dan agresivitas fisik memiliki skor yang relatif sama. Perilaku agresi verbal sering dianggap hal yang umum dalam sebuah pertemanan, padahal perilaku agresi fisik bisa terjadi berawal dari agresi verbal (Chaq, Suharnan, \& Rini, 2018). Agresi verbal diantaranya mengucapkan kata-kata hinaan atau mengejek, memaki dengan kata-kata kotor, melecehkan, mengancam, membentak, atau bahkan memerintah (Stevani, 
Basaria, \& Irena, 2018).

Sejalan dengan temuan menunjukan serangan yang dilakukan atlet biasanya berupa serangan secara fisik atau verbal (Maxwell, 2007). Lebih jauh agresivitas yang ada pada atlet merupakan upaya yang dilakukan untuk mempertahankan kedudukan atau mempertahankan poin yang didapat diluar ketentuan dalam bertanding. Atlet olahraga beladiri mengekspresikan agresivitasnya dengan cara memukul lawan sacara berlebihan, memaki, mengolok-olok, mengabaikan, bahkan melakukan protes jika juri atau wasit mengasumsikan bahwa memiliki keterpihakan dengan lawan dari atlet (Dvikaryani, Ni \& Jannah, 2019). Individu yang mempunyai kontrol diri rendah cenderung senang untuk melakukan suatu hal yang beresiko (seperti perilaku agresi verbal) (Aroma \& Suminar, 2012). Intervensi psikologis Assertive Behavior Therapy dapat menurunkan perilaku agresi verbal (Stevani et al., 2018), mematangkan emosi (Guswani \& Kawuryan, 2011), meningkatkan kontrol diri (Denson, DeWall, \& Finkel, 2012) dan kepribadian yang positif dapat diterapkan dalam latihan atletatlet PON Papua dalam menurunkan perilaku agresi yang negatif. Pengembangan agresivitas yang diperlukan dalam memenangkan pertandingan bukan untuk kecurangan atau frustasi.

Rekomendasi yang diperlukan dalam upaya pencapaian prestasi maksimal pada PON 2021 dengan meningkatkan berbagai keterampilan psikologis; kontrol kecemasan, agresivitas, kepercayaan diri, motivasi, pengelolaan stress, sikap positif, konsentrasi (Nopiyanto \& Dimyati, 2018; M. F. Dongoran \& Kalalo, 2020), meningkatkan kecerdasan emosi dalam mengontrol agresivitas (Setiawati, 2015), mengelola kecemasan dalam olahraga (Yane, 2016). Upaya itu meski harus dilakukan secara sistematis dan kontinu dalam bentuk latihan mental agar progres sesuai output yang diharapkan. Dalam hal ini atlet olahraga beladiri Provinsi Papua perlu mengoptimalkan pengelolaan kecemasan dan agresivitas yang positif untuk meningkatkan prestasi olahraga pada PON ke-XX di Tanah Papua.

\section{SIMPULAN}

Tingkat kecemasan dan agresivitas atlet cabang olahraga beladiri Provinsi papua pada PON 2021 berada pada tingkat medium atau sedang. Analisis lebih jauh pada Tingkat kecemasan menunjukan dimensi Kecemasan Kognitif jauh lebih tinggi dibandingkan kecemasan somatik. Sedangkan pada tingkat agresivitas menunjukan agresivitas verbal memiliki skor paling tinggi dibandingkan dimensi agresivitas fisik dan lainya. Penelitian ini tidak menganalisis lebih mendalam mengenai pengaruh intensitas kecemasan dan agresivitas terhadap prestasi maupun variabel lainnya. Untuk itu penelitian lanjutan yang lebih kompleks harus dilakukan agar bermanfaat dalam perkembangan olahraga prestasi atlet di Indonesia.

\section{DAFTAR PUSTAKA}

Agustiar, 0., \& Sultoni, K. (2016). Hubungan tingkat kecemasan dengan hasil pukulan gate-in pada olahraga woodbalL. JTIKOR (Jurnal Terapan Ilmu Keolahragaan), 1(2), 64-69.

Ahmad, M., \& Diana, R. (2015). Partisipasi Dalam Beladiri Karate dan Agresivitas Anak Di Institut Karate-Do Indonesia (INKAI). Jurnal Psikologi Integratif, 1(1).

Amani, M. (2019). Identifikasi motivasi pelajar perempuan mengikuti olahraga beladiri. Jurnal Pendidikan Olahraga Dan Kesehatan, 7(3).

Amir, N. (2012). Pengembangan alat ukur kecemasan olahraga. Jurnal Penelitian Dan Evaluasi Pendidikan, 16(1), 325-347.

Ardianto, M. (2013). Kecemasan pada pemain futsal dalam menghadapi turnamen. EMPATHY Jurnal Fakultas Psikologi, 2(1). 
Arifin, R. (2017). Peranan Mental dalam Prestasi Olahraga. Peranan Mental Dalam Prestasi Olahraga, 1.

Aroma, I. S., \& Suminar, D. R. (2012). Hubungan antara tingkat kontrol diri dengan kecenderungan perilaku kenakalan remaja. Jurnal Psikologi Pendidikan Dan Perkembangan, 1(2), 1-6.

Athan, A. N., \& Sampson, U. I. (2013). Coping with pre-competitive anxiety in sports competition. European Journal of Natural and Applied Sciences, 1(1), 1-9.

Azwar, S. (2012). Reliabilitas \& Validitas Edisi 4. Yogyakarta: Pustaka Belajar.

Boostani, M. A., \& Boostani, M. H. (2012). Investigation and comparing aggression in athletes in non-contact (swimming), limited contact (karate) and contactable (kickboxing) sport fields. Journal of Combat Sports and Martial Arts, 2(2), 87-89.

Buss, A. H., \& Perry, M. (1992). The aggression questionnaire. Journal of Personality and Social Psychology, 63(3), 452.

Carysa, Y. T. (2019). Pengaruh regulasi emosi terhadap agresivitas pada atlet sepak bola usia remaja. Universitas Sanata Dharma, Skripsi.

Chaq, M. C., Suharnan, S., \& Rini, A. P. (2018). Religiusitas, Kontrol Diri dan Agresivitas Verbal Remaja. FENOMENA, 27(2).

Cox, R. H., Martens, M. P., \& Russell, W. D. (2003). Measuring anxiety in athletics: the revised competitive state anxiety inventory-2. Journal of Sport and Exercise Psychology, 25(4), 519-533.

Denson, T. F., DeWall, C. N., \& Finkel, E. J. (2012). Self-control and aggression. Current Directions in Psychological Science, 21(1), 20-25.

Dongoran, M. F., \& Kalalo, C. N. (2020). Profil psikologis atlet pekan olahraga nasional (pon) papua menuju pon xx tahun 2020. Journal Sport Area, 5(1), 13-21.

Dongoran, M., Nopiyanto, Y., Saputro, D., \& Nugroho, A. (2019). Comparison of Psychological Skills of Pencak Silat and Boxing Athletes (Study on Indonesian Training Camp athletes). In International Conference on Social Science 2019 (ICSS 2019) (pp. 182-186). Atlantis Press.

Dosil, J. (2006). The sport psychologist's handbook: A guide for sport-specific performance enhancement. John Wiley \& Sons.

Dvikaryani, Ni \& Jannah, M. (2019). Hubungan antara Regulasi Emosi dengan Agresivitas Atlet Tinju Batalyon Artileri Pertahanan Udara Sedang 8. Character: Jurnal Penelitian Psikologi, 7, 1-7.

Gorner, K., Makarowski, R., \& Roskova, M. (2021). Aggression among Slovak males training in martial arts versus other sports disciplines. Ido Movement for Culture. Journal of Martial 
Journal of Sport Education (JOPE), 3 (2) 2021 - 123

Muhammad Fadli Dongoran ${ }^{1 *}$, Emaluel Lewar ${ }^{2}$, Ibrahim³ ${ }^{3}$, Guntur Yuli Satria ${ }^{4}$

Arts Anthropology, 21(2).

Guswani, A. M., \& Kawuryan, F. (2011). Perilaku agresi pada mahasiswa ditinjau dari kematangan emosi. Jurnal Psikologi UMK: PITUTUR, 1(2), 86-92.

Hasibuan, B. S., \& Kasih, I. (2015). Hubungan Antara Kecemasan Dan Agresivitas Dengan Prestasi Olahraga Beladiri Tarung Derajat Pada Atlet Petarung Putra. Jurnal Fisioterapi, 15(02).

Hendrayana, R. A. (2020). Analisis deskriptif aspek psikologis atlet panahan pelatda pon jawa barat xx 2021-papua. JURNAL ILMU KEOLAHRAGAAN, 19(2), 213-222.

Hermawati, L. R. (2014). Profil perilaku sosial atlet cabang olahraga bela diri, cabang olahraga permainan dan cabang olahraga konsentrasi. Universitas Pendidikan Indonesia.

Ilsya, M. N. F. (2016). Hubungan antara kecemasan sebelum bertanding dengan performa atlet pada cabang olahraga bolabasket. Universitas Pendidikan Indonesia.

Jannah, M. (2016). Kecemasan olahraga: Teori, pengukuran, dan latihan mental. Surabaya: Unesa University Press.

Jannah, M. (2017). Kecemasan dan konsentrasi pada atlet panahan. Jurnal Psikologi Teori Dan Terapan, 8(1), 53-60.

Kadek Sri Harta Dvikaryani, Ni Jannah, M. (2020). Hubungan antara regulasi emosi dengan agresivitas atlet tinju batalyon artileri pertahan udara sedang. Character: Jurnal Penelitian Psikologi., 7(3).

Kalinin, R., Balazsi, R., Pentek, I., Duica, Ștefania, \& Hantiu, I. (2019). Relationship between competitive anxiety and mental toughness: a latent regression analysis. Health, Sports \& Rehabilitation Medicine, 20(2), 70-74.

Kar, S. (2013). Measurement of Competition Level Anxiety of College Level Athletes by Using SCAT. Certified International Journal of Engineering Science and Innovative Technology, 9001(3), 2319-5967.

Kardiyanto, D. W. (2014). Faktor Penyebab Terjadinya Agresivitas Saat Bertanding pada Atlet Sepakbola Pekan Olahraga Pelajar Daerah (Popda) Kab Sumenep. Phederal: Physical Education, Health and Recreation Journal, 8(1), 13939.

Krishnaveni, K., \& Shahin, A. (2014). Aggression and its influence on sports performance. International Journal of Physical Education, Sports and Health, 1(2), 29-32.

Kumar, M. (2017). Study of Contact Game Sports Person in Context to Aggressive Tendency Mahesh Kumar C.R.M. Jat. College, Hisar Haryana India, 7, 139-142.

Kurtovic, N., \& Savova, N. (2016). Optimization of performance in top-level athletes during the kumite in sport karate. Journal of Sports Science, 4, 132-149.

Kusnierz, C., \& Bartik, P. (2014). The impact of practice of selected combat sports on signs of 
aggression in players in comparison with their non-training peers. Journal of Combat Sports \& Martial Arts, 5(1).

Kusuma, D. W. Y., Mulyono, A., \& Wirayudha, D. (2019). Comparison of Athletes Personality between Martial Art Sports in Central Java. RA JOURNAL OF APPLIED RESEARCH, 5(3), 2357-2361.

Mabweazara, S. Z., Andrews, B. S., \& Leach, L. L. (2014). Changes in state anxiety prior to competition: sport and exercise psychology. African Journal for Physical Health Education, Recreation and Dance, 20(Issue-21), 492-499.

Maulana, Z., \& Khairani, M. (2017). Kecemasan bertanding pada atlet pon acehberdasarkan jenis aktivitas olahraga. Jurnal Ilmiah Psikologi Terapan, 5(1), 97-106.

Maxwell, J. P. (2007). Development and preliminary validation of a Chinese version of the Buss-Perry Aggression Questionnaire in a population of Hong Kong Chinese. Journal of Personality Assessment, 88(3), 284-294.

Muhammad, N., Khan, M., \& Khan, W. (2020). Effect of different types of Anxiety on Athletes Performance; Planning and Managing Strategy to cope with Athletes' Anxiety. City University Research Journal, 10(3), 471-486.

Nikseresht, A., Yabande, A. A., Rahmanian, K., \& Jahromi, A. S. (2017). Pre-competition anxiety score among elite boy swimmers in Iran. World Family Medicine Journal: Incorporating the Middle East Journal of Family Medicine, 99(4216), 1-6.

Nilasari, D. D., Syafrial, S., \& Illahi, B. R. (2020). Motivasi dan Sarana Prasarana Latihan Atlet Provinsi Bengkulu Menuju PON XX Papua. SPORT GYMNASTICS: Jurnal Ilmiah Pendidikan Jasmani, 1(2), 30-36.

Nopiyanto, Y. E., \& Dimyati, D. (2018). Karakteristik psikologis atlet Sea Games Indonesia ditinjau dari jenis cabang olahraga dan jenis kelamin. Jurnal Keolahragaan, 6(1), 69-76.

Novian, S. (2013). Profil Tingkat Agresivitas Karateka UKM KKI PI. Universitas Pendidikan Indonesia.

Nurhuda, K., \& Jannah, M. (2018). Pengaruh meditasi mindfulness terhadap mental toughness pada atlet lari 400 m. Character: Jurnal Penelitian Psikologi., 5(3).

Purnamasari, A. D., Febriani, A. R., \& Kusnandar, K. (2020). Kecemasan pada atlet cabang olahraga bela diri (nomor tarung). Physical Activity Journal (PAJU), 2(1), 56-69.

Putra, M. F. P., \& Ita, S. (2019). Gambaran kapasitas fisik atlet Papua: Kajian menuju PON XX Papua. Jurnal Keolahragaan, 7(2), 135-145.

Radea, D. (2014). Analisis perbandingan tingkat kepercayaan diri dan agresivitas antara atlit pencak silat kategori tanding tunggal ganda dan regu kota bandung. UPI Bandung, (Skripsi).

Radochonski, M., Cynarski, W., Perenc, L., \& Siorek-Maślanka, L. (2011). Competitive anxiety 
and coping strategies in young martial arts and track and field athletes. Journal of Human Kinetics, 27(1), 180-189.

Ratumakin, R. (2019). Target 78 emas, dasarnya apa. Jubi. Retrieved from https://jubi.co.id/target-78-emas-dasarnya-apa/

Ree, M. J., French, D., MacLeod, C., \& Locke, V. (2008). Distinguishing cognitive and somatic dimensions of state and trait anxiety: Development and validation of the State-Trait Inventory for Cognitive and Somatic Anxiety (STICSA). Behavioural and Cognitive Psychotherapy, 36(3), 313.

Retnoningsasy, E., \& Jannah, M. (2020). Hubungan antara Mental Toughness dengan Kecemasan Olahraga pada Atlet Badminton. Character: Jurnal Penelitian Psikologi., 7(3).

Reza, A. B. (2012). Comparing the incidence of aggression among student athletes in various sports disciplines at the University of Tiran. Procedia-Social and Behavioral Sciences, 47, 1869-1873.

Setiawati, R. (2015). Hubungan antara kecerdasan emosi dengan perilaku agresi remaja. Universitas muhammadiyah surakarta.

Shachar, K., Ronen-Rosenbaum, T., Rosenbaum, M., Orkibi, H., \& Hamama, L. (2016). Reducing child aggression through sports intervention: The role of self-control skills and emotions. Children and Youth Services Review, 71, 241-249.

Shahar, K. (2011). Leaving Anger on the Field: Statistics show that sports help ease aggression in boys. Unpublished PhD: Https://Www. Sciencedaily. Com/Releases/2011/07/110706195908. Htm (Accessed 14th November 2017).

Stevani, S., Basaria, D., \& Irena, F. (2018). Penerapan Assertive Behavior Therapy Untuk Menurunkan Perilaku Agresi Verbal Pada Anak Di Lembaga X. Jurnal Muara Ilmu Sosial, Humaniora, Dan Seni, 2(1), 205-214.

Syahlan, F. N. (2016). Hubungan kecerdasan emosional dengan tingkat agresivitas atlet judo. Universitas Pendidikan Indonesia.

Usman, K. (2019). Peralatan modifikasi olahraga dasar pendidikan jasmani tingkat sekolah dasar. In SEMINAR NASIONAL PGSD UNIMED (Vol. 2, pp. 175-181).

Verawati, I., \& Sari, R. M. (2018). Tingkat agresivitas atlet pencak silat sumatera utara mengikuti pekan olahraga wilayah ix di bangka belitung. Sains Olahraga: Jurnal Ilmiah Ilmu Keolahragaan, 2(1), 19-30.

Vertonghen, J., \& Theeboom, M. (2010). The social-psychological outcomes of martial arts practise among youth: A review. Journal of Sports Science \& Medicine, 9(4), 528.

Vertonghen, J., Theeboom, M., \& Pieter, W. (2014). Mediating factors in martial arts and combat sports: an analysis of the type of martial art, characteristics, and social background of young participants. Perceptual and Motor Skills, 118(1), 41-61. 
Journal of Sport Education (JOPE), 3 (2) 2021 - 126

Muhammad Fadli Dongoran ${ }^{1 *}$, Emaluel Lewar ${ }^{2}$, Ibrahim ${ }^{3}$, Guntur Yuli Satria4

Wagiran. (2015). Metodologi Penelitian Pendidikan. Yogyakarta: Deepublish.

Wenda, Y. (2019). Papua yakin tembus 5 besar PON 2020. Https://Jubi.Co.Id/Papua-YakinTembus-5-Besar-Pon-2020/.

Yane, S. (2016). Kecemasan dalam olahraga. Jurnal Pendidikan Olah Raga, 2(2), 188-194.

Zadkhosh, S. M., Zandi, H. G., \& Hemayattalab, R. (2018). Neurofeedback versus mindfulness on young football players anxiety and performance. Turkish Journal of Kinesiology, 4(4), 132-141. 